\title{
Moral Disengagement and the Motivational Gap in Climate Change
}

\author{
Wouter Peeters $^{1}$ (D) $\cdot$ Lisa Diependaele ${ }^{2} \cdot$ Sigrid Sterckx $^{2}$
}

Accepted: 23 April 2019 /Published online: 29 April 2019

(C) The Author(s) 2019

\begin{abstract}
Although climate change jeopardizes the fundamental human rights of current as well as future people, current actions and ambitions to tackle it are inadequate. There are two prominent explanations for this motivational gap in the climate ethics literature. The first maintains that our conventional moral judgement system is not well equipped to identify a complex problem such as climate change as an important moral problem. The second explanation refers to people's reluctance to change their behaviour and the temptation to shirk responsibility. We argue that both factors are at play in the motivational gap and that they are complemented by crucial moral psychological insights regarding moral disengagement, which enables emitters to dissociate self-condemnation from harmful conduct. In this way, emitters are able to maintain their profligate, consumptive lifestyle, even though this conflicts with their moral standards with respect to climate change. We provide some illustrations of how strategies of moral disengagement are deployed in climate change and discuss the relationship between the explanations for the motivational gap and moral disengagement. On the basis of this explanatory framework, we submit that there are three pathways to tackle the motivational gap and moral disengagement in climate change: making climate change more salient to emitters and affirming their self-efficacy; reconsidering the self-interested motives that necessitate moral disengagement; and tackling moral disengagement directly.
\end{abstract}

Keywords Climate change $\cdot$ Moral disengagement · Motivational gap · Individual responsibility Consumption

Wouter Peeters

w.peeters@bham.ac.uk

1 Centre for the Study of Global Ethics, Department of Philosophy, University of Birmingham, ERI Building (148), B15 2TT Birmingham, UK

2 Bioethics Institute Ghent, Department of Philosophy and Moral Sciences, Faculty of Arts and Philosophy, Ghent University, Blandijnberg 2, 9000 Ghent, Belgium 


\section{Introduction}

In its most recent Special Report, the Intergovernmental Panel on Climate Change (IPCC $2018,59)$ unambiguously states that total global warming has reached $1.0{ }^{\circ} \mathrm{C}$, and that this warming is entirely attributable to human activities. Already occurring and future predicted impacts of climate change on human life include increased mortality, food and water insecurity, the spread and exacerbation of diseases, conflicts resulting from resource scarcity, and increased migration (IPCC 2014, 2018; Watts et al. 2018; WHO 2018). Climate change thus jeopardizes the fundamental human rights of current as well as future people, including their rights to life, health, adequate food and water, adequate housing, and self-determination (Bell 2013; Office of the United Nations High Commissioner for Human Rights 2009).

The 2015 Paris Agreement on Climate Change reaffirms the essential goal of holding the increase in global temperature to well below $2{ }^{\circ} \mathrm{C}$ above pre-industrial temperature, while pursuing efforts to limit the temperature increase to $1.5^{\circ} \mathrm{C}$ (UN 2015, Article 2). However, current policies, presently in place around the world, are still projected to result in about $3.3{ }^{\circ} \mathrm{C}$ warming by the end of the century, and the combined pledges (expressed in the Intended Nationally Determined Contributions) under the Paris Agreement would still lead to a median warming of $3.0^{\circ} \mathrm{C}$ (Climate Action Tracker 2019b). According to the rating of Climate Action Tracker (2019a), the pledges of most countries - including all developed countries - are incompatible with the $2{ }^{\circ} \mathrm{C}$-target. The United Nations Environmental Programme (UNEP 2018,21 ) calculates that emissions reductions that are roughly 2 to 3 times higher than current pledges are needed to bridge the gap with $2{ }^{\circ} \mathrm{C}$-pathways, and reductions 5 times higher are necessary to align emissions with $1.5^{\circ} \mathrm{C}$-pathways.

Hence, there is a notable discrepancy between the severity of climate change's impacts and the current lack of motivation to adequately abate the threat, which can be called a motivational gap. A prominent explanation in the climate ethics literature maintains that the causes for the lack of motivation to tackle climate change can be traced to the complexity of climate change and the ineptitude of our moral judgement system to identify it as an important moral problem (Jamieson 2006, 476-7; 2013, 39; 2014, 148-50; Markowitz and Shariff 2012, 243). Jamieson $(2010$, 436-437) argues that climate change is not conceptualised as an urgent moral problem because it does not present the characteristics of a paradigm moral problem: 'climate change is not a matter of a clearly identifiable individual acting intentionally so as to inflict and identifiable harm on another identifiable individual, closely related in time and space.' Another common explanation holds that people's motivation generated by their moral standards and their sincere moral judgement is trumped by weakness of will and/or unwillingness to abide by their moral judgement. They may resent the behavioural changes that are required to effectively mitigate climate change (Stoll-Kleemann et al. 2001, 112), and are therefore tempted to pass the buck onto future people, the poor and nature, rather than undertaking action themselves (Gardiner 2011a, 45). Worth remembering in this context is the declaration of former U.S. President George Bush Senior at the 1992 Earth Summit in Rio de Janeiro that 'the American lifestyle is not up for negotiation' (quoted in Singer 2002b, 2).

In this paper, we will argue that these two explanations are both at play in the motivational gap and that they are complemented by crucial moral psychological insights regarding moral disengagement. People's conduct is kept in line with their moral judgement by self-reactive influences: people ordinarily do things that give them self-satisfaction, while refraining from behaving in ways that violate their moral standards because it will bring self-condemnation (Bandura 1991, 69; 2016, 1). 
However, mechanisms of moral disengagement allow such self-regulation to be disengaged from reprehensible conduct, by reconstructing one's reprehensible conduct or the moral issue at hand. The complexity of climate change and the ineptitude of our moral judgement system to identify complex problems such as climate change as important moral imperatives (emphasised by the first explanation of the motivational gap) provides the necessary latitude for emitters to deploy mechanisms of moral disengagement. The (self-)deceptive and biased reasoning embodied by mechanisms of moral disengagement in turn facilitates a reconstruction of climate change and one's contribution to it, allowing people to continue emitting greenhouse gases, rather than having to make fundamental lifestyle or policy changes to reduce greenhouse gas emissions (emphasised by the second explanation of the motivational gap), without feeling or being held accountable for the harmful effects of climate change. Moral disengagement thus facilitates the motivational gap and allows it to persist by reducing or removing the inconsistency that would otherwise arise between moral judgement and self-interested conduct that conflicts with it.

We only focus on mitigating climate change by reducing greenhouse gas emissions. Successfully responding to climate change will also involve other mitigation strategies (such as sink enhancement) as well as adaptation and compensation, yet these measures fall beyond the scope of this paper. In our view, effectively reducing total greenhouse gas emissions will depend on substantial actions undertaken by all actors (including international institutions, national and regional governments, corporations, civil society organisations, and individuals) who have agency in reducing greenhouse gas emissions, and to the extent that these actors have this kind of agency. We will mainly focus on individual emitters and assume that they can be held accountable for their profligate emissions. ${ }^{1}$ While individuals cannot be faulted for the greenhouse gases they emit in order to meet their basic needs, and many of their choices are determined by contextual factors that are beyond their control (such as infrastructure, cultural expectations, and the energy regime) (Gardiner 2011b, 46; Shue 2001, 451), we will hold that they can be held accountable for their profligate emissions. More precisely, individual emitters do have at least some agency in climate change mitigation, because they can reduce profligate or unnecessary emissions, for example by decreasing their consumption of animal products, ${ }^{2}$ or their energy consumption by undertaking fairly low-cost and easy actions (including motor vehicle maintenance, using public transportation, switching from bathing to showering, and line drying of clothes) - the so-called low-hanging fruit (Gardner and Stern 2008; Gilligan et al. 2010; Vandenbergh et al. 2008). ${ }^{3}$

\footnotetext{
${ }^{1}$ According to Gardner and Stern $(2008,13)$ and Vandenbergh et al. $(2008,1703)$, individuals and households account for $30-40 \%$ of total greenhouse gas emissions in the USA.

${ }^{2}$ By now, it is well-known that the consumption of animal products via the livestock supply chain is an important contributor to global warming: estimations range from $14.5 \%$ of annual global greenhouse gas emissions (Gerber et al. 2013, 15) to 51\% (Goodland and Anhang 2009, 11). Garnett (2009, 496-7) argues that in poor societies with serious problems of mal- and undernutrition, keeping a goat, a pig, or a few chickens can make a critical difference to the adequacy of people's diet. It is fairly uncontroversial, however, that in many developed societies (where adequately nutritional plant foods are sufficiently available), it is perfectly feasible for most people to follow a diet low in animal products and still be well-nourished.

${ }^{3}$ Shue $(1993,2001)$ famously distinguishes between subsistence emissions and luxury emissions. In general, we are in agreement with Shue's account, yet often the objection has been raised that this distinction involves an important line-drawing problem. Since we do not have space here to fully do justice to this issue, we merely assume that individual emitters can at least be held accountable for profligate or clearly unnecessary greenhouse gas emissions for which feasible alternatives exist - emissions that would unambiguously classify as luxury emissions.
} 
This paper makes a novel contribution to the debate about the motivational gap in climate change in three significant respects. First, a few notable exceptions notwithstanding, ${ }^{4}$ the deployment of moral disengagement remains underexplored in the climate ethics literature. In order to contribute to filling this gap, in the following section, we will first briefly explain our meta-ethical assumptions and how moral disengagement fits in, and then illustrate how some mechanisms of moral disengagement are being deployed in climate change. Second, by bringing climate ethics and moral psychology together, we aim to improve the understanding of the motivational gap in climate change. Third, we explore how this explanatory framework informs strategies to tackle moral disengagement and the motivational gap. We will work towards the latter two aims in the third section, after which we will highlight the main points of our discussion in the conclusion.

\section{Mechanisms of Moral Disengagement in Climate Change}

\subsection{Meta-Ethics and Moral Disengagement}

The connection between moral judgement and moral motivation is the subject of a long-standing philosophical disagreement in meta-ethics. Although we cannot fully do justice to this intricate debate here, some conceptual remarks might clarify our assumptions about the motivational force of moral judgement and the role of moral disengagement in the motivational gap.

The first explanation of the motivational gap draws on the dominant understanding of moral motivation in contemporary philosophy: according to internalism, a sincere moral judgement necessarily entails motivation to abide by it (Buckwalter and Turri 2017, 434; Rosati 2016, 3.2). From this perspective, the observation that many people fail to see climate change as an urgent moral problem - and lack the motivation to address it - indicates that our moral judgement system is inadequate to identify complex moral problems such as climate change as urgent moral problems and to instigate action (Jamieson 1992, 148; 2013, 39; 2014, 147; Markowitz and Shariff 2012). Jamieson $(2013,44)$ indeed explicitly affirms the internalist view, which leads him to explain the lack of motivation to act on climate change as a failure of our moral judgement system.

In contrast to Jamieson, Gardiner $(2013,102-103)$ is willing to take externalism seriously, which holds that 'agents might grasp the moral severity of a particular action perfectly well and so possess a justifying reason not to do it - and yet not be motivated accordingly.' Indeed, externalism can easily enough explain the lack of motivation to tackle climate change: one can endorse the moral judgement that climate change poses a threat to human rights without being motivated to act, simply because the connection between moral judgement and motivation is purely contingent (Buckwalter and Turri 2017, 435; Rosati 2016, 3.2). The second explanation of the motivational gap, according to which people act on their self-interested motives rather than on motives generated by their moral standards, is easily supported by the externalist account of moral motivation.

\footnotetext{
${ }^{4}$ Some of the illustrations Bandura $(2007,2016$, chapter 8$)$ discusses to argue that selective moral disengagement impedes ecological sustainability apply to climate change. Stoll-Kleemann et al. (2001) provide empirical evidence of similar psychological processes in focus group research in Switzerland. Graça et al. (2014) provide empirical evidence of how mechanisms of moral disengagement hinder the reduction of meat consumption. Markowitz and Shariff $(2012,244)$ mention a guilty bias: to allay negative recriminations, individuals engage in biased reasoning to minimize perceptions of their complicity. Peeters et al. (2015) provide an overview that illustrates the deployment of all mechanisms of moral disengagement in climate change.
} 
However, both positions remain unsatisfactory: we agree with Gardiner $(2011 \mathrm{~b}, 42)$ that internalism as formulated above is controversial, but so is an externalist rejection of the conceptual connection between moral judgement and motivation. We would therefore argue that there is an alternative possibility: within internalism, an important distinction can be made between strong internalism and weak internalism. Both views hold that a sincere moral judgement necessarily entails motivating reasons for action, but the distinction lies in whether this moral motivation overridingly motivates people to comply with their moral judgement. On the strong version of internalism, a person who makes a sincere moral judgement will be overridingly motivated by her judgement (Rosati 2016, 3.2). However, this assumption is overly strong, and contemporary moral philosophers commonly accept some form of weak internalism, which holds that even though the person who makes a sincere moral judgement will necessarily feel some motivation to act accordingly, this moral motivation can be overridden (Buckwalter and Turri 2017, 434-435; Rosati 2016, 3.2). First, the motivation to comply with one moral principle may be overridden by the motivation to comply with another moral principle. This refers to the much broader problem of conflict between moral principles, which falls beyond the scope of this paper. Hare (1981, 57-62) subsumes two further instances of moral motivation being overridden under the heading of 'taking a moral holiday': on the one hand, the motivation to abide by one's moral judgement may be defeated by weakness of will and other mental maladies; and on the other hand, competing, self-interested desires may entail motivation to act which is stronger than the motivation entailed by one's sincere moral judgement (also see Rosati 2016, 3.2).

In the case of climate change, however, we would submit that it is often unclear whether the motivation to abide by one's moral judgement is thwarted by weakness of will or by motivation stemming from self-interested desires. Moreover, to some extent, acting on selfinterested desires rather than abiding by one's sincere moral judgement is predicated on weakness of will, since strong-willed people will not so easily allow their moral motivation to be overridden by self-interested motives. Consider again the two instances of profligate emissions mentioned in the introduction above, which we believe that individuals could easily reduce. First, it is often unclear whether people's motivation to continue consuming animal products (when sufficient adequate alternatives are available) in the face of climate change arises from an akratic attitude (given by habitual consumption, or lack of time to explore alternatives) or self-interested desires (an unwillingness to reduce the consumption of animal products due to, for example, a strong preference for meat or an aversion to vegetarian or vegan lifestyles). Second, regarding profligate energy consumption, we similarly believe that both weakness of will (for example related to habits or the perceived demandingness of behavioural changes) and self-interested motives (such as comfort) lie at the basis of people's inaction regarding the low-hanging fruit.

Hence, weak internalism seems to give a more nuanced account of moral motivation: in contrast to externalism, it does not rely on a controversial rejection of the assumption that a sincere moral judgement necessarily entails at least some motivation to abide by it, but in contrast to strong internalism, weak internalism accepts that such moral motivation can be overridden. Nonetheless, it does not readily explain how moral motivation is thwarted by weakness of will and/or motivation stemming from self-interested desires, or how the resulting inconsistency between moral judgment and conduct that goes against it is managed. It is here that our main interest for this paper lies and we consider insights from moral psychology, and especially Bandura's work on moral agency and moral disengagement, to be highly significant in explaining these processes. 
Indeed, according to Bandura $(2016,1)$, a full understanding of morality 'must explain not only how people come to behave morally, but also how they can behave inhumanely and still retain their self-respect and feel good about themselves.' Moral conduct is motivated and regulated by the on-going exercise of self-reactive influence: behaving in accordance with personal and societal moral standards is supported by positive self-sanctions (including selfrespect and rewarding oneself), whereas violating one's moral standards would result in negative self-sanctions (such as feelings of guilt or remorse and self-punishment) (Bandura $2002,102 ; 2016,1,29)$. Hence, by deploying these self-sanctions, it is this self-regulatory system that links moral reasoning to moral action (Bandura 2002, 101-102) and thus provides the motivation to comply with one's moral judgement.

However, these self-regulatory mechanisms do not operate unless they are activated, and there are many psycho-social manoeuvres by which moral self-sanctions can be disengaged from reprehensible conduct (Bandura 2002, 102; 2016, 2). The goal of these mechanisms of moral disengagement is to - consciously or unconsciously - convince oneself and others that one's reprehensible conduct still falls within moral standards through changing the perception of one's actions or reconstructing the situation. In other words, moral disengagement enables people to compromise their moral standards and to engage in unethical behaviour, while retaining their sense of moral integrity and not having to face self-condemnation or social disapproval (Bandura 1991, 71-72; 2016, 2). Moral disengagement allows people to rationalise their reprehensible behaviour, and thus permits weakness of will and/or self-interested desires to thwart their moral motivation to abide by their moral judgement. A substantial body of evidence has indeed demonstrated the disinhibitory power of moral disengagement (see for example Bandura 2016; Bandura et al. 2001; Barsky 2011; Bersoff 1999; Bustamante and Chaux 2014; Graça et al. 2014; Kish-Gephart et al. 2013; Paciello et al. 2013). ${ }^{5}$

At this point it is worth mentioning that Gardiner (2011a, chapter 9) influentially discusses a similar phenomenon, which he calls moral corruption. According to him, people face strong temptation to pass the buck of climate change onto the poor, the future and nature, but they are reluctant to face up to moral criticism for succumbing to it and they are therefore likely to be attracted to weak or deceptive arguments that appear on the surface to license the buckpassing. Gardiner (2011a, 301-302) argues further that even if people accept that climate change poses a serious moral challenge, our resolve to tackle it is threatened by 'corruption that targets our ways of talking and thinking, and so prevents us from even seeing the problem in the right way.' He then goes on to illustrate this phenomenon of moral corruption by drawing parallels with the Dashwoods' self-serving reasoning in Jane Austen's Sense and Sensibility (Gardiner 2011a, chapter 9). His examples are different from those we discuss below, but it should be clear that our analysis of moral disengagement confirms Gardiner's diagnosis and complements his account of moral corruption by drawing on significant insights from moral psychology.

\footnotetext{
${ }_{5}^{5}$ Referring to Barnes (1985), Singer (2002a, 70-72) mentions conditioned ethical blindness, which might be taken to relate to moral disengagement as well. Barnes $(1985,160)$ illustrates this concept with reference to the discrepancy he experienced between on the one hand using animals in research (and being rewarded for this without questioning the morality involved) and consuming meat as food, while on the other hand being kind to his pets and tending to sick animals. Although discussing the conditioning by professional rewards falls beyond the scope of this paper, it is useful to point out that the compartmentalisation and dubious justification described by Barnes substantially overlaps with moral disengagement.
} 
An important insight shared between Gardiner's account of moral corruption and our illustrations of how moral disengagement is deployed in climate change is the following issue. He mentions that the problem involved in moral corruption

'is not quite that the values or arguments are bad or mistaken considered simply as such; instead, they would be good values and correct arguments in a more limited context, but are misappropriated or badly applied. ... If one can twist or pervert otherwise plausible moral claims to a corrupt end, then one can both hoodwink some into thinking that they do right when they do wrong, and also provide moral cover for the more discerning.' (Gardiner 2011a, 307-308).

Similarly, as we will illustrate in the following subsections, strategies of moral disengagement typically invoke arguments that are not entirely invalid or manifestly misguided, but the application of these arguments to exonerate emitters from accountability for the effects of their profligate emissions is deceitful and unjustified.

We are convinced that all mechanisms of moral disengagement discussed by Bandura and other moral psychologists are deployed in climate change, but we only have space here to discuss some of them that are used pervasively in the public discourse as illustrations, namely discrediting evidence of harm, advantageous comparison, diffusion of responsibility, and displacement of responsibility.

\subsection{Discrediting Evidence of Harm}

Climate change and its effects have frequently been subject to outright denial - for example by Donald Trump, who has dismissed global warming as a Chinese hoax ${ }^{6}$ - even in the face of overwhelming scientific evidence to the contrary. European politicians who deny climate change include prominent British Conservative politicians Michael Gove and Nigel Lawson (Ward 2016), and former French President Nicholas Sarkozy (Dagorn 2016). Also consider that the oil industry, the political right in the USA, conservative think tanks, and a network of doubt-mongers have played a pivotal role in the dissemination of unscientific claims and unfounded scepticism about global warming, which have led to an informational bias towards scepticism and denial in much of the United States' mainstream media (Oreskes and Conway 2010, chapter 6).

Indeed, there appears to be a significant gap between the actual scientific consensus and the public perception thereof. Cook et al. (2016) report that over $97 \%$ of climate scientists in the peer-reviewed scientific literature endorse the consensus on anthropogenic global warming, while the number of papers rejecting it is a minuscule proportion of the published research. In contrast, in June 2016, only a minority (27\%) of Americans believed that almost all scientists agree that climate change is caused by human activity, another $35 \%$ said that more than half of climate scientists agree about this, $20 \%$ believed that fewer than half of scientists agree on the anthropogenic causes of climate change, and $15 \%$ of Americans said that almost no scientific experts believe that human behaviour is the main contributing factor in climate change (Funk and Kennedy 2016).

In fact, it can be argued that there is a disproportionate focus on scientific uncertainty and disagreement in climate change, while much of it is manufactured or grossly exaggerated in

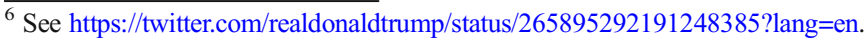


order to create the false impression that some conclusions are much less widely accepted by scientists than they actually are (Vanderheiden 2008, 197). Despite overwhelming evidence to the contrary, doubt and controversy are created in order to discredit the evidence of the harm emitters are causing, which facilitates the evasion of accountability: 'as long as the harmful results of one's conduct are ignored, minimised, or the evidence is discredited, there is little reason for self-censure to be activated' (Bandura 2007, 21). Moreover, in addition to clearly being unrealistic, demanding full scientific certainty merely serves as a convenient justification for inaction or postponed action (Bandura 2007, 21; Gifford 2011, 292) - even though in the face of the possibly catastrophic impacts of climate change, inaction is a dangerous way of dealing with any remaining uncertainty. Rather, as the UNFCCC clearly states, 'the Parties should take precautionary measures to anticipate, prevent or minimize the causes of climate change and mitigate its adverse effects. Where there are threats of serious or irreversible damage, lack of full scientific certainty should not be used as a reason for postponing such measures ...' (UN 1992, article 3, emphasis added).

In sum, although some scientific uncertainties remain and clearly complicate matters, they do not impede a general normative evaluation of the causes of climate change and the threats it poses to the enjoyment of human rights. Rather, discrediting evidence of harm is a mechanism of moral disengagement used to evade blame for the causal contribution of one's greenhouse gas emissions to the harmful impacts of climatic changes.

\subsection{Advantageous Comparison}

People often consider their greenhouse gas emissions to be a by-product of their ordinary, everyday activities. Indeed, Sinnott-Armstrong (2005, 290, emphasis added) states that individuals should not be held accountable for harms 'by calling their acts causes of harms when their acts are not at all unusual, assuming that they did not intend the harm.' He discusses the example of recreational driving in a fuel-intensive car and concludes: 'it is not unusual to go for joyrides. Such drivers do not intend any harm. Hence, we should not see my act of driving on a sunny Sunday afternoon as a cause of global warming or its harms' (Sinnott-Armstrong 2005, p. 290).

Sinnott-Armstrong $(2005,290)$ argues that condemnation should be reserved for the worst offenders, because if agents who are doing no worse than average are condemned, then the worst offenders would have no incentive to improve their acts, because even should they reduce their activities to average levels, they could still expect to remain subject to blame (Sinnott-Armstrong 2005, 290). However, we consider this argumentation to be flawed. First, although many greenhouse gas emitting activities ostensibly seem usual in the local context of developed countries, they are unusual in a global context. Worldwide data about outings in a fuel-intensive car are lacking, but consider for example meat consumption. In 2013, an average of 70 and $115 \mathrm{~kg}$ of meat was consumed per capita in Belgium, respectively the USA, while the world average was merely $43 \mathrm{~kg}$ (FAO 2018). Although eating large quantities of meat does not appear to be unusual in the context of Belgium or the USA, it is rather unusual in a global context. Since climate change is a global problem, greenhouse gas emitting acts should be scrutinized with reference to the global context, rather than a specific geographical or economic background. Meat consumers in Belgium and the USA should effectively be held accountable according to Sinnott-Armstrong's own heuristic - contrary to his argument because they are among the worst offenders in the global context. Second, and more importantly, even if greenhouse gas emitting activities were usual in the global context, this would 
still not exonerate emitters from responsibility, because it would be an instance of the ad populum fallacy. The mere fact that many other people engage in an act does not render it harmless. In other words, the mere usualness of a greenhouse gas emitting activity is an inadequate basis to conclude that it is morally permissible.

We do not deny that part of the challenge climate change poses to our moral judgement system is indeed that greenhouse gases are emitted by seemingly ordinary, everyday activities. However, we believe that Sinnott-Armstrong's argument corresponds to the mechanism of moral disengagement called advantageous comparison. People routinely compare their actions with those of others, and derive subjective and descriptive norms from their observations about what the proper course of action is (Gifford 2011, 294). The perception of behaviour is coloured by what it is compared against, and by exploiting this contrast principle, reprehensible conduct can be made to seem righteous (Bandura 1991, 80; 2002, 105). Invoking the usualness of greenhouse gas emitting activities would render each greenhouse gas emitting activity self-excusing if, and merely because, it is sufficiently common. Moreover, SinnottArmstrong's (2005) pragmatic heuristic to only blame the worst offenders unmistakably encourages the search for and comparison with people who emit more greenhouse gases, which would allegedly exculpate one's own purportedly usual emissions.

Hence, rather than convincingly exonerating emitters' culpability, reference to the usualness of their greenhouse gas emitting activities amounts to a mere rationalization.

\subsection{Diffusion of Responsibility}

Climate change is a collective action problem, in which at least according to some authors (including Cripps 2013, 119-124; Johnson 2003, 273; Sandler 2010, 168; Sinnott-Armstrong 2005, 289) an individual's greenhouse gas emissions appear entirely faultless, since, taken separately, their effects are insignificant. The greenhouse gases of any particular individual make no observable contribution to global warming, which seems to lead to the conclusions that (i) there is nothing morally wrong with individuals emitting greenhouse gases, because they do not cause any harms; and (ii) that individuals cannot make a difference by undertaking individual actions to reduce their emissions. Gifford and Comeau $(2011,1305)$ indeed find that $47 \%$ of respondents cited 'lack of perceived behavioral control' when asked why they did not do something about climate change.

However, this view is problematic. Hiller (2011, 352-3) convincingly argues that individual greenhouse gas emitting activities are at least prima facie wrong because the expected amount of harm is greater than not emitting: there will be a positive expected net increase in the amount of climate change. Due to the complexity of the causal processes underlying climate change, it is of course impossible to trace back a particular harm resulting from climatic changes to a particular greenhouse gas molecule emitted by a particular agent, yet it is clear that even an individual's emissions provide a fully real - albeit infinitesimal - contribution to global warming.

To this perspective on individual emitters' contribution to climate change, two important objections can be raised, neatly summarised by Sinnott-Armstrong (2005, 289, emphasis added): 'global warming will not occur unless lots of other people also expel greenhouse gases. So my individual act [i.e. an outing in a fuel-intensive car] is neither necessary nor sufficient for global warming.' Hence, it is first claimed that climate change is a matter of overdetermined positive causation: climate change will occur, whether or not individual $X$ emits greenhouse gases. Second, the claim that individual $X$ 's emissions are insufficient to 
cause climate change assumes that emissions cause harm only after their accumulation in the atmosphere exceeds a certain threshold.

Our responses to these objections start from the observation that climate change is already occurring, resulting in significant harmful impacts, and additional emissions of greenhouse gases cause further detrimental climatic changes. Hence, the question is not whether climate change will occur, but rather how much climate change will occur. ${ }^{7}$ Against the first charge that $X$ 's emissions are not necessary to cause climate change, we argue that climate change indeed occurs without $X$ 's greenhouse gas emissions, yet that these emissions nonetheless further exacerbate climate change in an infinitesimal but fully real way. Against the second objection that $X$ 's emissions are not sufficient to cause climate change, we should like to point out that there are indeed a number of thresholds related to climate change, which, once crossed, may lead to an abrupt worsening of climate change, yet even below such thresholds, climate change already has significant harmful impacts, and $X$ 's emissions again contribute to these impacts in a fully real - albeit infinitesimal - way. Relative to preindustrial levels, global warming has reached $1.0{ }^{\circ} \mathrm{C}$ in 2017 (IPCC 2018, 59), which has already led to significant climatic changes adversely impacting human life, and any additional emissions of greenhouse gases cause further detrimental climatic changes. Moreover, the IPCC (2018, 186-212) has observed trends in the intensity and frequency of some temperature and weather extremes since the mid-twentieth century as a result of only $0.5{ }^{\circ} \mathrm{C}$ of global warming. In this light, rather than considering individuals' emissions to be morally insignificant, their contribution to the accumulation of greenhouse gases in the atmosphere and to the resulting climate-related harms is fully real.

Undeniably, part of the complexity of climate change is that the greenhouse gas emissions of a large number of individuals and other agents contribute to it. However, we should also resist the temptation to try to exonerate individuals emitters' culpability by construing the contribution of their greenhouse gases to the problem as morally insignificant, because it amounts to a well-known strategy of moral disengagement: in problems of collective action, an individual's contribution to an aggregate harmful effect seems trivial and any harm done by a group of people can always largely be ascribed to the behaviour of the others in the group (Bandura 1991, 85). In this way, the exercise of moral self-control is weakened, because personal agency is obscured by diffusing responsibility for detrimental behaviour (Bandura 2002, 107; 2007, 19).

This mechanism and the problem of collective action are rather familiar in issues of global justice: as observed by Shue (1996, 112-13), the complexity involved in many systemic deprivations feeds the temptation to reason that, since they are the responsibility of practically everyone, 'they are the responsibility of no one in particular, least of all oneself. No one needs to change until after everyone else changes, it seems.' Similarly, Miller $(2008,120)$ notes that if we leave the collective duty to tackle climate change undistributed, 'we fall into the familiar trap whereby no particular person or group of persons has a defined obligation, and each can excuse him- or herself from taking steps to combat climate change by passing the responsibility to someone else.'

\footnotetext{
${ }^{7}$ Another line of argumentation in the debate holds that treating the emissions of an individual as entirely faultless involves at least two mistakes in moral mathematics as described by Parfit (1987, 70-83): ignoring the effects of sets of acts and ignoring imperceptible effects (see e.g. Schwenkenbecher 2014; Vanderheiden 2008, $160-167)$. Reconstructing this debate falls beyond the scope of this paper, but it is useful to point out that these sophisticated objections against the view that individual emission are entirely faultless are complementary to our more practical ones.
} 
Although the mechanism of diffusing responsibility is most obvious at the individual level, it also explains the inertia at the international level in the context of the UNFCCC: a large number of disparate parties all have to cooperate to come to a comprehensive agreement containing robust and often costly measures to tackle climate change (Harris 2007). In this context, it is tempting to minimise the contribution of one's own country to the problem and emphasise other countries' contributions. Consider for example that an important argument for then-US President George W. Bush's rejection of the Kyoto Accord was that it did not set any standards for developing countries such as China and India (Sanger 2001). Similarly, in his speech announcing the USA's withdrawal from the Paris Agreement, President Donald Trump stated that in comparison with China and India, the Paris Agreement is unfair to the USA (Trump 2017, paragraphs 10-14).

In sum, even though climate change is a collective action problem, this does not exonerate individuals: individual emitters can and should be held accountable for the fully real contribution of their profligate emissions to the problem.

\subsection{Displacement of Responsibility}

Climate change is a collective action problem, and in general, the establishment or improvement of collective institutions is taken to be the best solution to collective action problems. Indeed, citizens - rightfully - expect guidance of their national governments regarding greenhouse gas emissions reductions, and those governments as well as international institutions can and should be blamed for their lack of ambition. Klein $(2014,212)$ considers 'the idea that change is something that is handed down from above by our betters, rather than something we demand ourselves' to be one of the greatest psychological barriers to climate action. However, this cannot justify complacency: if our argument in the previous section is sound and an individual's emissions indeed provide a fully real - albeit infinitesimal contribution to global warming, then this implies that even in the absence of effective (trans)national policies to tackle climate change, individual emitters retain culpability for the effects of the emissions that are a result of their profligate lifestyle. Moreover, it would be too simplistic to relegate all responsibility for reducing greenhouse gas emissions to the collective level, because 'what states do must be carried out ultimately by individuals' (Lichtenberg 2014 , 9). In addition, individual reductions of greenhouse gas emissions may actually signal support for environmental policies to the collective (policy) level: for example, if more people cycle, politicians would be more inclined to invest in cycling infrastructure (which, in turn, is likely to lead to more people cycling).

Hence, the need for collective measures to tackle climate change does not let individuals off the hook. ${ }^{8}$ Relegating all duties to tackle climate change to the collective level in order to attempt to exonerate individual emitters from accountability for the effects of their profligate emissions amounts to moral disengagement through displacing responsibility: they are seemingly spared self-condemnation for the harmful effects of climate because they do not perceive themselves to be responsible for their greenhouse-gas emitting activities (Bandura 1991, 81; 2002, 106).

\footnotetext{
${ }^{8}$ Moreover, if an individual emitter wants to invoke the argument that it is the task of the government and supranational institutions to address climate change, she at the very least has the obligation to vote for parties that represent the most likely chance of success to see such policies effectively implemented (De Smet et al. 2016; Maltais 2013, 602).
} 
Also note that displacement of responsibility in climate change does not only occur in the relationship between individual emitters and collective institutions, but also in other ways. For example, individual consumers often contend that companies should improve their production processes and, vice versa, companies shift blame to consumers, arguing that they primarily want products at low prices. Individual emitters may also blame all other individual emitters, and could find some ammunition in the argument regarding positive causal overdetermination discussed in the previous subsection. However, as we have seen, this argument fails because every individual's emissions exacerbate climate change in an infinitesimal but fully real way. ${ }^{9}$ Also consider that politicians often try to justify inaction by arguing that their electorate opposes more robust climate policy measures.

As we stated in the introduction, we believe that climate change is so great a challenge that effectively addressing it will depend on substantial actions undertaken by all actors who have agency in reducing greenhouse gas emissions, and to the extent that these actors have this kind of agency. Hence, even though it is correct to point out the responsibilities of other agents (for example, collective institutions), such argument cannot be employed to exonerate the culpability of any particular agent (such as individual emitter $X$ ), because this would amount to moral disengagement.

\section{Addressing Moral Disengagement and the Motivational Gap}

There is no silver bullet to tackle the motivational gap; increasing ambitions of individual emitters and other agents for addressing climate change will require a multi-strategic approach. This approach will have to include addressing moral disengagement, since it is a significant factor in the motivational gap. We agree with Bandura (2007, 32), when he concludes that 'if we are to be responsible stewards of our environment for future generations, we must make it difficult to disengage moral sanctions from ecologically destructive practices.' Unfortunately, in contrast to the vast body of research providing conceptual analysis and empirical evidence of moral disengagement, relatively little research has explored interventions to tackle it (Bustamante and Chaux 2014, 55, 59; Moore 2015, 202). In this section, our aim is therefore twofold: we will elucidate how moral disengagement relates to the explanations of the motivational gap offered in the climate ethics literature in order to provide a comprehensive explanatory framework for the motivational gap, and explore how this informs strategies for reducing moral disengagement in climate change.

\subsection{Moral Disengagement and the Complexity of Climate Change}

The first explanation for the motivational gap maintains that our moral judgement system is not well-equipped to identify climate change as an important moral imperative or morally intense issue (Jamieson 2006, 476-7; 2010, 436-7; Markowitz and Shariff 2012, 243). As mentioned in the introduction, Jamieson $(2010$, 436-438; 2014, 168-169) argues that people

\footnotetext{
${ }_{9}^{9}$ Jamieson $(2014,171-173)$ argues that climate change will occur whether or not an emitter $X$ needlessly or thoughtlessly engages in greenhouse-gas emitting activities. For virtually every emitter $X$, he maintains, there is a group which does not include $X$ such that if it were to act differently, then climate change would not occur. Even though we agree that climate change is already happening, whether or not $X$ engages in further greenhouse-gas emitting activities, this argument fails to take into account that even then, $X$ 's emissions contribute to further worsening climate change.
} 
do not tend to conceptualize climate change as an urgent moral problem because it is not accompanied by the characteristics of a paradigm moral problem: the harmful effects of climate change are not easily identifiable, they are not the result of intentional acts, and victim and perpetrator are not closely related in time and space. He therefore concludes that viewing climate change as a problem of individual moral responsibility requires a revision of our everyday understandings of individual responsibility.

We fully agree that the inherent complexity of climate change - including the remaining scientific uncertainties, the fact that greenhouse gas emissions are the by-product of seemingly ordinary, usual activities, and the need for collective action of a large number of diverse agents - poses a challenge to our moral judgement system. However, this explanation of the motivational gap does not take into account people's ability to psychologically reconstruct a situation in order to reduce its moral intensity (Barsky 2011, 61), or, in other words, to disengage moral self-sanctions from their harmful conduct (in this case, greenhouse gas emitting activities) (see also Bandura 1991, 81-2). It should be noted, first, that these otherwise plausible claims about the complexity of climate change are also invoked to exonerate individual emitters from their accountability for the effects of their profligate emissions, but that this particular application of these arguments is unjustified and deceitful (see also Bersoff 1999, 37). As Gardiner, 2011a, b, 307) argues with respect to his diagnosis of moral corruption in climate change, rather than being entirely mistaken, the problem is that these arguments are misappropriated to serve corrupt ends. Second, Bersoff $(1999,37)$ notes that 'the less moral ambiguity there is surrounding a situation, the less latitude an agent has in negotiating reality in such a way as to provide justification for an unethical action.' The inherent complexity of climate change precisely provides the necessary ambiguity and latitude for emitters to reconstruct the problem of climate change and their contribution to it. Gardiner (2011a, 46, emphasis in original) indeed confirms that 'since climate change involves a complex convergence of problems, it is easy to engage in manipulative or self-deceptive behavior' - which amounts to moral disengagement.

Consider for example that the causes and effects of climate change are dispersed in space and time, in the sense that greenhouse gases emitted from any geographical location affect the climate globally and into the future (Gardiner 2011a, 23; Jamieson 2014, 102). This obviously creates a significant amount of ambiguity, complicating sound moral judgements about causality and the culpability of individual emitters. However, the literature and the general audience appear to take this argument a step further and often perceive the causes and effects of climate change as remote in space and time. For example, Markowitz and Shariff (2012, $244)$ and Leiserowitz $(2006,50)$ note that many people in developed nations believe that climate change will most negatively affect individuals who live in faraway places, or far in the future, or both. However, whereas the dispersal of causes and effects means that greenhouse gases emitted anywhere and anytime affect the climate globally and into the future, the spatial and temporal remoteness is an inaccurate depiction of climate change: concerns about vulnerability to the harmful impacts of climate change do not apply only to people who live remote in space or time (Gardiner 2011b, 45; Jamieson 2010, 439).

First, although future people will likely suffer most, climate change's harmful impacts are already massively affecting human life today. The IPCC $(2014,49)$ states that in recent decades, changes in climate have caused impacts on natural and human systems on all continents and across the oceans.' Watts et al. (2018, 585-595) report already observable health impacts related to climate change, including a $46 \%$ increase in the frequency of weather-related disasters between 1990 and 1999 and 2007-2016, a massive increase in 
dengue virus transmission and related morbidity and mortality, and significant agricultural yield losses (especially in regions with high vulnerability to undernutrition).

Second, climate change not only affects people living in distant places, but also in the developed world. For example, climate change is already contributing to the burden of disease and premature deaths in Europe, mainly by increasing the frequency and intensity of extreme weather events (especially heat waves), changes in the distribution of climate-sensitive diseases, and changes in environmental and social conditions (EEA 2017, 199-222). In the USA, the amount of precipitation falling in very heavy events has markedly increased from 1958 to 2012, for example by $71 \%$ in the Northeast (Melillo et al. 2014, 37).

Hence, although the dispersion of causes and effects of climate change contributes to its complexity, emphasis on the spatial and temporal remoteness of its harmful effects turns out to be a deceitful characterization of climate change that facilitates moral disengagement. As Bandura $(2016,64)$ observes, 'it is easier to harm others when their suffering is not visible and when destructive actions are physically and temporally remote from their effects.'

We will discuss two main pathways to address these issues in order to increase people's moral motivation to contribute to combatting climate change: first, making climate change and its negative effects more salient to individual emitters; and second, increasing people's perception of self-efficacy.

The first strategy consists of reducing climate change's complexity by making it more salient and more personally relevant to individual emitters. Moser and Dilling $(2006,503)$ and Weber $(2015,562-563)$ point out that since the perceived immediacy and personal relevance of threats play a large role in the willingness to take action, connecting climate change to individual emitters is likely to increase their motivation to act on climate change. Therefore, communicators should address the inaccurate perception of climate change's impacts as remote in space and time, and highlight that climate change is already affecting people living here and now (Leiserowitz 2006, 53-55; Moser and Dilling 2006, 500). Leiserowitz (2006, 55-56) argues that articulating and emphasising the projected impacts on human health in particular is likely to elevate public concerns about climate change. Empirical studies by KishGephart et al. (2013) indeed find that making the harm to others salient can reduce the likelihood that people will morally disengage, because humans have developed a natural tendency to automatically recognize and respond empathetically when others are being harmed. Similarly, Paciello et al. $(2013,6)$ find that 'the more participants were concerned about others in need the less they relied upon cognitive maneuvering that obscured their personal responsibility.'

In contrast, overly dire messages and inducing fear, anxiety or personal distress about climate change might backfire by evoking counterproductive responses, including moral disengagement (Fida et al. 2016, 5; Markowitz and Shariff 2012, 245; Moore 2015, 200; Moser and Dilling 2006, 496; Paciello et al. 2013, 6-7). Therefore, rather than appealing to fear and anxiety to communicate urgency, communicators should tap into the desire of people to not just be part of the problem, but part of the solution: 'people want to know what they can do, that they are able to do it, and that others are doing their share as well' (Moser and Dilling 2006, 505).

The second pathway to increase the moral motivation of individual emitters is therefore to point out that they do have agency in tackling climate change and show them what to do and how to do it. Communicators could emphasise that individuals' emissions are a fully real contribution to the accumulation of greenhouse gases in the atmosphere and to the resulting climate-related harms (see section 2.4 above), rather than being insignificant. In this way, the 
savings potential of reducing meat and dairy consumption, and of actions that reduce energy consumption - the so-called low-hanging fruit (including motor vehicle maintenance, showering instead of bathing, and line drying of clothes) - could be highlighted.

However, Moser and Dilling $(2006,505)$ argue that merely identifying possible actions will be inadequate for all but the most motivated and committed people: 'for most individuals, what is required to actually implement these actions is empowerment through a sense of selfefficacy ..., social support or peer pressure ... or modelling by others...' We would submit that especially empowerment through self-efficacy should be pursued, because it impedes moral disengagement. According to Bandura (2016, 5) and Bandura et al. (2001, 125), perceived self-efficacy is the foundation of human aspirations, motivation, well-being, and personal accomplishments. It plays a pivotal role in the process of self-management because it affects actions directly: people who do not believe that they can produce desired effects by their actions (low perceived self-efficacy) have little incentive to act or to persevere in the face of difficulties. A strong sense of self-efficacy, in contrast, affects behaviour in large part 'by promoting prosocialness, curtailing the propensity to disengage moral self-sanctions from socially alienating and harmful conduct, and countering ruminative and vengeful affectivity' (Bandura et al. 2001, 125). Hence, perceived self-efficacy not only leads people to engage to a lesser extent in transgressive conduct, but also makes moral disengagement less accessible (Fida et al. 2016, 14).

The magnitude and complexity of climate change clearly overwhelm us, very much reducing people's feelings of self-efficacy and perceived behavioural control (see also section 2.4 above). Increasing people's perception of agency and self-efficacy will thus be crucial to addressing the motivational gap and tackling moral disengagement. Essential to this will be countering the perception that individual actions do not make a difference, and, in contrast, emphasising that every individual contribution counts (see also Cismaru et al. 2011, 80). As Jamieson (2006, 481-482) eloquently puts this:

We must begin from where we are - changing ourselves, changing our leaders, and changing our institutions - but from here we can change the world. Biking instead of driving or choosing the veggieburger rather than the hamburger may seem like small choices, and it may seem that such small choices by such little people barely matter. But ironically, they may be the only thing that matters. For large changes are caused and constituted by small choices. And in the end, however things turn out, it is how we live that gives meaning and significance to our lives.

In addition, Cismaru et al. (2011, 80-81) recommend increasing people's perception of selfefficacy by providing them with reasons to believe that they can adopt recommendations for action and success stories from others, connecting climate change with other priority issues, and decreasing the perceived costs by making it easier for people to implement the recommendations for action and proposing a step-by-step plan from easy-to-follow to more costly actions.

In sum, according to one explanation in the climate ethics literature for the motivational gap, the complexity inherent to climate change prevents us from identifying it as an important moral imperative, and leads individual emitters to believe that their individual contributions are insignificant. However, this complexity also facilitates moral disengagement by providing the necessary latitude to reconstruct the problem and one's contribution to it. We suggest tackling these problems by making climate change and its harmful impacts more salient to people, as 
well as by increasing people's perception of self-efficacy with respect to climate change mitigation.

\subsection{Moral Disengagement and Akratic or Self-Interested Motives}

Gardiner (2011a, 31) and Jamieson $(1992,147)$ argue that action on climate change raises fundamental and uncomfortable questions about who we are, what we want to be and what kinds of societies we want. By selectively disengaging the self-regulatory system, moral disengagement allows one to dodge these questions, and to maintain a consumptive lifestyle high in greenhouse gas emissions without feeling or being held accountable for its harmful effects.

There is a disjunction between the need to mitigate climate change and the personal preference for a particular, materialistic lifestyle high in greenhouse gas emissions: people may feel anxiety over climate change, but resent the changes in behaviour that are required to effectively mitigate climate change (such as using public transportation or reducing energy and meat consumption) (Stoll-Kleemann et al. 2001, 99). Similarly, Graça et al. (2014) find that mechanisms of moral disengagement play a significant role in resolving the inconsistency between people's concern for environmental sustainability, animal welfare, and health on the one hand, and cherished food practices high in meat consumption on the other hand. Consistent with the theory of moral disengagement, these rationalisations defuse feelings of guilt and self-censure, and are associated with the lack of willingness to consider transitioning toward less harmful dietary choices (Graça et al. 2014, 761). In general, the opportunity costs involved in shifting away from consumptive lifestyles high in greenhouse gas emissions are perceived as daunting (Stoll-Kleemann et al. 2001, 107; Klein 2014, 212) and moral disengagement allows emitters to avoid this shift without feeling or being held accountable for the resulting climate-related harms.

In order to address the motivational gap, we should therefore try to reconceptualise human flourishing, away from materialism and a lifestyle high in greenhouse gas emissions, and towards a direct focus on quality of life. The apparent trade-off between acting proenvironmentally and pursuing well-being can be reduced by showing that beyond the point of ensuring the material preconditions for subsistence, material wealth has relatively little relationship to wellbeing (Brown and Kasser 2005, 349-350; Jackson 2009, 15, 143; Kasser $2002,4)$. This holds the promise that by consuming less, we could not only contribute to tackling climate change, but also live better (Jackson 2005, 25). There are two sides to this coin, both of which may motivate people to move away from materialism and a lifestyle high in greenhouse gas emissions: first, consuming less will reduce the negative consequences of consumerism for personal and collective wellbeing; and second, consuming less will open up the possibility to pursue important non-material aspects of wellbeing.

First, materialism may have become the prevailing model of the good life, but it has also generated significant costs to personal and collective wellbeing: in addition to contributing to climate change, negative effects include noise, pollution, consumer anxiety, stench, work stress, and health risks (Soper 2007, 211, 221). Kasser (2002, chapter 2) provides empirical evidence underpinning the conclusion that strong materialistic values are associated with a pervasive undermining of people's personal well-being (including low life satisfaction, depression and anxiety, physical problems, and personality disorders). Communicators should draw more attention to these negative consequences of materialistic pursuits in order to motivate individual and societal change. 
Second, it should be emphasised that important pleasures and sources of gratification, such as leisure activities, interpersonal relationships, and cultural and political participation, are being lost, remain unrealized, or are thwarted by materialistic pursuits (Jackson 2009, 100 102 ; Kasser 2002, 72). Kasser (2002, chapter 7) also argues that rather than providing paths to freedom and autonomy, people feel chained and controlled when they focus on materialistic values. The most important sources of life satisfaction (including peace, freedom, community involvement, employment, recognition, personal growth, relationships and self-respect) are non-material in nature and rely only to a limited extent on the emission of greenhouse gases (Brown and Kasser 2005; Jackson 2009, 37; Lichtenberg 2014, 156). In addition, De Young (2000, 515-16) demonstrates that pro-environmental and pro-social behaviour are worth engaging in because of the intrinsic satisfaction they provide. Moving away from materialism and consumerism may open up opportunities, resources and time to pursue these important non-material aspects of wellbeing. In turn, the internalisation of values related to personal growth, close relationships, and contribution to one's community is likely to instigate a decline in materialism and a rise in personal wellbeing (Kasser 2002, 99).

Two important points should be noted. First, moving away from materialism and a lifestyle high in greenhouse gas emissions is not a simple task that can easily be realised by individual consumers: it is a fundamental social, cultural and economic project, not only requiring changes in individual values and pursuits, but also a change in the underlying structure of consumer society and policy interventions at different levels (Jackson 2005, 32-33; 2009, 167).

Second, it should be noted that the strategies mentioned here do not frame environmentally responsible behaviour in terms of self-sacrifice. The imperative to reduce greenhouse gas emissions has often been portrayed and perceived as constraining human welfare and threatening our quality of life. However, the apparent trade-off between a healthy environment and a happy life may make people less likely to behave in pro-environmental ways (Brown and Kasser 2005, 349-350). To avoid this, the strategies discussed here rather emphasise the possibility of a 'double dividend' of moving away from materialism - that is, reducing humanity's environmental impact as well as increasing quality of life (Jackson 2005, 25). Indeed, Gifford and Comeau (2011) provide empirical evidence confirming that exposure to motivational-oriented framing (including portrayal of improvements in quality of life resulting from positive lifestyle-changes, and involvement of solutions, values and visions) is associated with greater reported competence and climate change engagement than exposure to sacrificeoriented messages. Hence, portraying wellbeing and pro-environmental behaviour as compatible pursuits will significantly contribute to tackling moral disengagement and the motivational gap in climate change by reducing or even completely neutralising the (perceived) conflict between self-interest and moral standards.

\subsection{Addressing Moral Disengagement Directly}

The strategies discussed in the previous subsections will help reduce moral disengagement by reducing the ambiguity or latitude necessary to employ mechanisms of moral disengagement (section 3.1) and the need thereto (section 3.2). In addition, we would submit that moral disengagement should be addressed directly, which includes the following three strategies.

First, according to Jamieson (2006, 479), what we need to address climate change is 'a sense of ownership and identification with the outcomes that our actions produce,' which 'allows us to overcome the alienation from the collective consequences of our actions.' The 
abundant and pervasive deployment of moral disengagement forms a formidable obstacle to successfully responding to climate change, because it is precisely such biased reasoning that enables the alienation from the consequences of one's conduct.

In Jamieson's (2006, 480-1; 2014, 185-93) view, obtaining this sense of ownership and identification with the outcomes of our actions requires cultivating certain green virtues, including humility, temperance, mindfulness, cooperativeness, and respect for nature. However, even appealing to people's moral character does not form a fail-safe antidote against moral disengagement, since, as Bandura (2016, 26-27) notes, moral disengagement can resolve conflicts between virtues and reprehensible conduct as well, by enabling virtuous individuals to behave in harmful ways but still retain a self-view as virtuous.

We would nonetheless submit that cultivating the particular virtue mindfulness might be helpful in tackling moral disengagement, because it encourages reflection on the consequences of one's actions. In this way, mindfulness may prevent alienation from the outcomes of our action, and be conducive to gaining the sense of ownership of the outcomes of our actions Jamieson deems essential for climate change mitigation. When people are mindful, internal and external realities are perceived openly and without distortion (Brown and Kasser 2005, 351; Jamieson 2006, 480; 2014, 187). Hence, rather than thoughtlessly emitting greenhouse gases and being morally disengaged from the harmful consequences, mindful people appreciate the proximate as well as remote effects of their actions on the climate (Jamieson 2006, 480; 2014, 187).

Second, a better general understanding of moral psychology and the ability to recognise mechanisms of moral disengagement by others and oneself may render people less inclined to deploy such biased reasoning. According to Gardiner (2011a, 301), 'serious moral agents strive to protect themselves against rationalization, self-deception, and moral manipulation.' For people who generally see themselves as moral and honest, and for whom moral integrity is important, a better understanding of moral disengagement might erode much of the attractiveness of the biased reasoning involved. People may be more self-critical and less prone to deploying moral disengagement if they are aware that it is merely a kind of (self-)deception. McAlister (2001) indeed found that persuasive communication educating people about moral disengagement and promoting resistance to it reduces individuals' tendencies to disengage. Bustamante and Chaux $(2014,55)$ were unable to replicate McAlister's (2001) results regarding persuasive education, but they do provide evidence for the hypothesis that developing critical thinking enables questioning beliefs or justifications that make it easy for people to resort to moral disengagement. This research also suggests that if more people become more critical and less willing to accept their self-justifications, this may create a system of social regulation, which can be useful for stopping moral disengagement by making the mechanisms visible to others.

Finally, action on climate change should be linked to positive moral emotions, which might decrease defensive processing of daunting information about the state of the world, and allow individuals to recognize tackling climate change in a rewarding rather than discouraging manner (Markowitz and Shariff 2012, 245). In the previous sections, we already suggested that communicators should focus on enhancing people's perceived self-efficacy, rather than on dire messages about climate change (section 3.1), as well as portray wellbeing and proenvironmental behaviour as compatible pursuits, rather than using sacrifice-oriented messages (section 3.2). These strategies are likely to curtail moral disengagement. In addition, feelings of competence and pride are strong motivators for action (De Young 2000; Williams and DeSteno 2008), and reduce moral disengagement (Markowitz and Shariff 2012, 245). 


\section{Conclusion}

Selective moral disengagement allows people to engage in conduct that goes against their moral judgment without having to face moral self-condemnation or social disapproval. In the context of climate change, moral disengagement allows emitters to continue emitting greenhouse gases, rather than having to make fundamental lifestyle changes, while retaining their self-worth and without feeling accountable for climate-related harms. We indeed illustrated that at least the strategies of discrediting evidence of harm, advantageous comparison, diffusion of responsibility, and displacement of responsibility are used in the public discourse regarding climate change.

These findings are of substantial relevance for climate ethicists, policy-makers, communicators and environmental psychologists who aim to close the motivational gap in climate change. For one, these insights contribute to a more comprehensive understanding of the motivational gap. The climate ethics literature has advanced two main explanations: on the one hand, it has been argued that our moral judgement system is not well equipped to identify climate change as an important and urgent moral issue; and on the other hand, it has been argued that akratic or self-interested motives to maintain a materialistic lifestyle appear to often gain the upper hand over moral standards. Moral disengagement connects these explanations: otherwise valid arguments about the complexity of climate change are misappropriated to exonerate individual emitters from their accountability for the effects of their profligate emissions. Moreover, the complexity inherent to climate change provides the necessary latitude for individual emitters to reconstruct the problem of climate change and their contribution to it by means of moral disengagement, which in turn allows them to engage in greenhouse gas emitting activities without feeling accountable for the adverse effects of climate change.

We have argued that on the basis of this comprehensive explanatory framework there are three groups of strategies that may help tackling moral disengagement and the motivational gap in climate change. First, the problem of the inherent complexity of climate change can be tackled by making climate change more salient and personally relevant for individual emitters, and by increasing their perceived self-efficacy. These strategies will not only increase people's motivation to tackle climate change, but also reduce (the opportunity for) moral disengagement. Second, self-interested motives can be addressed by reconceptualising wellbeing, away from materialism and towards a direct focus on quality of life. This move can be motivated by pointing out the negative consequences of consumerism for personal and collective wellbeing, and the importance of non-material aspects of human flourishing, both of which contribute to framing wellbeing and pro-environmental behaviour as compatible pursuits. In this way, they are likely to contribute to tackling moral disengagement and the motivational gap in climate change by reducing or neutralising the (perceived) conflict between self-interests and moral standards. Third, moral disengagement should be addressed directly by cultivating mindfulness, promoting a better public understanding of moral disengagement, and linking actions on climate change to positive moral emotions.

Acknowledgements We would like to thank Julian Cockbain, Andries De Smet and Jo Dirix for their feedback on earlier versions of this paper. We are especially grateful to two anonymous reviewers for their insightful and constructive comments. 
Open Access This article is distributed under the terms of the Creative Commons Attribution 4.0 International License (http://creativecommons.org/licenses/by/4.0/), which permits unrestricted use, distribution, and reproduction in any medium, provided you give appropriate credit to the original author(s) and the source, provide a link to the Creative Commons license, and indicate if changes were made.

\section{References}

Bandura A (1991) Social cognitive theory of moral thought and action. In: Kurtines W, Gewirts J (eds) Handbook of moral behaviour and development. Volume 1: theory. Lawrence Erlbaum Associates, Hillsdale, pp 45-103

Bandura A (2002) Selective moral disengagement in the exercise of moral agency. J Moral Educ 31:101-119. https://doi.org/10.1080/0305724022014322

Bandura A (2007) Impeding ecological sustainability through selective moral disengagement. Int J Innov Sustain Dev 2:8. https://doi.org/10.1504/IJISD.2007.016056

Bandura A (2016) Moral disengagement. How people do harm and live with themselves. Worth Publishers, New York

Bandura A, Caprara G, Barbaranelli C, Pastorelli C, Regalia C (2001) Sociocognitive self-regulatory mechanisms governing transgressive behavior. J Pers Soc Psychol 80:125-135. https://doi.org/10.1037//00223514.80.1.125

Barnes D (1985) A matter of change. In: Singer P (ed) In defence of animals. Basil Blackwell, Oxford, pp 157167

Barsky A (2011) Investigating the effects of moral disengagement and participation on unethical work behavior. J Bus Ethics 104:59-75. https://doi.org/10.1007/s10551-011-0889-7

Bell D (2013) Climate change and human rights. WIREs Clim Change 4:159-170. https://doi.org/10.1002 /wcc. 218

Bersoff D (1999) Why good people sometimes do bad things: motivated reasoning and unethical behavior. Personal Soc Psychol Bull 25:28-39. https://doi.org/10.1177/0146167299025001003

Brown K, Kasser T (2005) Are psychological and ecological well-being compatible? The role of values, mindfulness, and lifestyle. Soc Indic Res 74:349-368. https://doi.org/10.1007/s11205-004-8207-8

Buckwalter W, Turri J (2017) In the thick of moral motivation. Rev of Philos Psychol 8:433-453. https://doi. org/10.1007/s13164-016-0306-3

Bustamante A, Chaux E (2014) Reducing moral disengagement mechanisms: a comparison of two interventions. J Lat/Lat Am Stud 6:52-54. https://doi.org/10.18085/1las.6.1.123583644qq115t3

Cismaru M, Cismaru R, Ono T, Nelson K (2011) "Act on climate change": an application of protection motivation theory. Soc Mark Q 17:62-84. https://doi.org/10.1080/15245004.2011.595539

Climate Action Tracker (2019a) Countries. https:/climateactiontracker.org/countries/. Accessed 16 April 2019

Climate Action Tracker (2019b). Temperatures. https:/climateactiontracker.org/global/temperatures/. Accessed 16 April 2019

Cook J, Oreskes N, Doran P, Anderegg W, Verheggen B, Maibach E, Carlton J, Lewandowsky S, Skuce A, Green S, Nuticelli D, Jacobs P, Richardson M, Winkler B, Painting R, Rice K (2016) Consensus on consensus: a synthesis of consensus estimates on human-caused global warming. Environ Res Lett 11. https://doi.org/10.1088/1748-9326/11/4/048002

Cripps E (2013) Climate change and the moral agent. Individual duties in an interdependent world. Oxford University Press, Oxford

Dagorn G (2016) Les volte-face de Nicolas Sarkozy sur le changement climatique. Le Monde (15 September 2016). http://www.lemonde.fr/les-decodeurs/article/2016/09/15/les-volte-face-de-nicolas-sarkozy-sur-lechangement-climatique_4998385_4355770.html. Accessed 16 April 2019

De Smet A, Peeters W, Sterckx S (2016) The delegated authority model misused as a strategy of disengagement in the case of climate change. Ethics Global Politics 9:29299. https://doi.org/10.3402/egp.v9.29299

De Young R (2000) Expanding and evaluating motives for environmentally responsible behavior. J Soc Issues 56:509-526. https://doi.org/10.1111/0022-4537.00181

EEA (2017) Climate change, impacts and vulnerability in Europe 2016. An indicator-based report. Publication Office of the European Union, Luxembourg. https:/www.eea.europa.eu/publications/climate-changeimpacts-and-vulnerability-2016/at_download/file. Accessed 16 April 2019

FAO. (2018) FAOSTAT. Food supply - livestock and fish primary equivalent. http://www.fao. org/faostat/en/\#data/CL. Accessed 16 April 2019 
Fida R, Tramontano C, Paciello M, Ghezzi V, Barbaranelli C (2016) Understanding the interplay among regulatory self-efficacy, moral disengagement, and academic cheating behaviour during vocational education: a three-wave study. J Bus Ethics 153:725-740. https://doi.org/10.1007/s10551-016-3373-6

Funk C, Kennedy B (2016) Public view on climate change and climate scientists. http://www.pewinternet. org/2016/10/04/public-views-on-climate-change-and-climate-scientists/. Accessed 16 April 2019

Gardiner S (2011a) A perfect moral storm: the ethical tragedy of climate change. Oxford University Press, Oxford

Gardiner S (2011b) Is no one responsible for global environmental tragedy? Climate change as a challenge to our ethical concepts. In: Arnold D (ed) The ethics of global climate change. Cambridge University Press, Cambridge, pp 38-59

Gardiner S (2013) Reflecting on a perfect moral storm. Philos and public issues (new Ser) 3(1):89-135

Gardner G, Stern P (2008) The short list: the most effective actions U.S. households can take to curb climate change. Environ. 50:12-25. https://doi.org/10.3200/ENVT.50.5.12-25

Garnett T (2009) Livestock-related greenhouse gas emissions: impacts and options for policy makers. Environ Sci \& Policy 12:491-503. https://doi.org/10.1016/j.envsci.2009.01.006

Gerber P, Steinfeld H, Henderson B, Mottet A, Opio C, Dijkman J, Falcucci A, Tempio G (2013) Tackling climate change through livestock - a global assessment of emissions and mitigation opportunities. FAO, Rome. http://www.fao.org/docrep/018/i3437e/i3437e.pdf. Accessed 16 April 2019

Gifford R (2011) The dragons of inaction. Psychological barriers that limit climate change mitigation and adaptation. Am Psychol 66:290-302. https://doi.org/10.1037/a0023566

Gifford R, Comeau L (2011) Message framing influences perceived climate change competence, engagement, and behavioral intentions. Global Environ Chang. 21:1301-1307. https://doi.org/10.1016/j. gloenvcha.2011.06.004

Gilligan J, Dietz T, Gardner G, Stern P, Vandenbergh M (2010) The behavioural wedge. Signif. 7:17-20. https://doi.org/10.1111/j.1740-9713.2010.00405.x

Goodland R, Anhang J (2009) Livestock and climate change: what if the key actors in climate change are ... cows, pigs, and chickens? World Watch Mag 22:10-19

Graça J, Calheiros M, Oliveira A (2014) Moral disengagement in harmful but cherished food practices? An exploration into the case of meat. J Agr Environ Ethics. 27:749-765. https://doi.org/10.1007/s10806-014-9488-9

Hare R (1981) Moral thinking. Its levels, method, and point. Oxford University Press, Oxford

Harris P (2007) Collective action on climate change: the logic of regime failure. Nat Resour J 47(1):195-224

Hiller A (2011) Climate change and individual responsibility. Monist 94:349-368. https://doi.org/10.5840 /monist201194318

IPCC (2014) Climate change 2014: synthesis report. Contribution of working groups I, II and III to the fifth assessment report of the intergovernmental panel on climate change [Core writing team, Pachauri R, Meyer L]. Geneva: IPCC. https://www.ipcc.ch/report/ar5/syr/. Accessed 16 April 2019

IPCC (2018) eGlobal warming of $1.5^{\circ}$ C. Geneva: IPCC. https://www.ipcc.ch/sr15/. Accessed 16 April 2019

Jackson T (2005) Live better by consuming less? Is there a "double dividend" in sustainable consumption? J Ind Ecol 9:19-36. https://doi.org/10.1162/1088198054084734

Jackson T (2009) Prosperity without growth. Economics for a finite planet. Earthscan, London

Jamieson D (1992) Ethics, public policy, and global warming. Sci Tech Hum Val 17:139-153. https://doi. org/10.1177/016224399201700201

Jamieson D (2006) The moral and political challenges of climate change) In: Moser S, Dilling L (eds) Creating a climate for change: communicating climate change \& facilitating social change. Cambridge University Press, Cambridge, pp 475-482

Jamieson D (2010) Climate change, responsibility, and justice. Sci Eng Ethics 16:431-445. https://doi. org/10.1007/s11948-009-9174-x

Jamieson D (2013) Jack, Jill, and Jane in a perfect moral storm. Philos and Public Issues (New Ser) 3(1):37-53

Jamieson D (2014) Reason in a dark time) Why the struggle against climate change failed - and what it means for our future. Oxford University Press, Oxford

Johnson B (2003) Ethical obligations in a tragedy of the commons. Environ Val. 12:271-287. https://oi. org/10.3197/096327103129341324

Kasser T (2002) The high price of materialism. The MIT Press, Cambridge

Kish-Gephart J, Detert J, Treviño L, Baker V, Martin S (2013) Situational moral disengagement: can the effects of self-interest be mitigated? J of Bus Ethics 125:267-285. https://doi.org/10.1007/s10551-013-1909-6

Klein N (2014) This changes everything: capitalism vs. the climate. Simon \& Schuster, New York

Leiserowitz A (2006) In: Moser S, Dilling L (eds) Creating a climate for change. Communicating climate change and facilitating social changeCommunicating the risks of global warming: American risk perceptions, affective images, and interpretive communities. Cambridge University Press, Cambridge, pp 44-63

Lichtenberg J (2014) Distant strangers. Ethics, psychology, and global poverty. Cambridge University Press, Cambridge 
Maltais A (2013) Radically non-ideal climate politics and the obligation to at least vote green. Environ Val 22: 589-608. https://doi.org/10.3197/096327113X13745164553798

Markowitz E, Shariff A (2012) Climate change and moral judgment. Nat Clim Chang 2:243-247. https://doi. org/10.1038/nclimate1378

McAlister A (2001) Moral disengagement: measurement and modification. J Peace Res 38:87-99. https://doi. org/10.1177/0022343301038001005

Melillo J, Richmond T, Yohe G (eds) (2014) Climate change impacts in the United States: the third National Climate Assessment. Washington: U.S. Global Change Research Program. http://nca2014.globalchange. gov/downloads. Accessed 16 April 2019

Miller D (2008) Global justice and climate change: how should responsibilities be distributed? The Tanner lectures on human values. https://tannerlectures.utah.edu/_documents/a-to-z/m/Miller_08.pdf. Accessed 16 April 2019

Moore C (2015) Moral disengagement. Curr Opin Psychol 6:199-204. https://doi.org/10.1016/j. copsyc. 2015.07 .018

Moser S, Dilling L (2006) Toward the social tipping point: creating a climate for change. In: Moser S, Dilling L (eds) Creating a climate for change. Communicating climate change and facilitating social change. Cambridge University Press, Cambridge, pp 491-516

Office of the United Nations High Commissioner for Human Rights (2009) Report of the Office of the United Nations High Commissioner for Human Rights on the relationship between climate change and human rights (A/HRC/10/61). http://www.refworld.org/docid/498811532.html. Accessed 16 April 2019

Oreskes N, Conway E (2010) Merchants of doubt: how a handful of scientists obscured the truth on issues from tobacco smoke to global warming. Bloomsbury Press, New York

Paciello M, Fida R, Cerniglia L, Tramontano C, Cole E (2013) High cost helping scenario: the role of empathy, prosocial reasoning and moral disengagement on helping behavior. Pers Individ Dif 55:3-7. https://doi. org/10.1016/j.paid.2012.11.004

Parfit D (1987) Reasons and persons [Ed. with corrections]. Oxford University Press, Oxford

Peeters W, De Smet A, Diependaele S, Sterckx S (2015) Climate change and individual responsibility. Agency, moral disengagement and the motivational gap. Palgrave MacMillan, Basingstoke

Rosati C (2016) Moral Motivation. In Zalta E (ed.). Stanford Encyclopedia of Philosophy. https://plato.stanford. edu/entries/moral-motivation/. Accessed 16 April 2019

Sandler R (2010) Ethical theory and the problem of inconsequentialism: why environmental ethicists should be virtue-oriented ethicists. J Agr Environ Ethics 23:167-183. https://doi.org/10.1007/s10806-009-9203-4

Sanger D (2001) Bush will continue to oppose Kyoto Pact on global warming. The New York Times (12 June 2001). https://www.nytimes.com/2001/06/12/world/bush-will-continue-to-oppose-kyoto-pact-onglobal-warming.html. Accessed 16 April 2019

Schwenkenbecher A (2014) Is there an obligation to reduce one's individual carbon footprint. Crit Rev Int Soc Pol Philos 17:168-188. https://doi.org/10.1080/13698230.2012.692984

Shue H (1993) Subsistence emissions and luxury emissions. Law Policy 15:39-60. https://doi.org/10.1111 /j.1467-9930.1993.tb00093.x

Shue H (1996) Basic rights: subsistence, affluence, and U.S. foreign policy [2 ${ }^{\text {nd }}$ Ed.; originally published in 1980]. Princeton University Press, Princeton

Shue H (2001) Climate. In: Jamieson D (ed) A companion to environmental philosophy. Blackwell, Malden, pp $449-459$

Singer P (2002a) Animal liberation. HarperCollins, New York

Singer P (2002b) One world: the ethics of globalisation. Yale University Press, New Haven

Sinnott-Armstrong W (2005) It's not my fault: global warming and individual moral obligations. In: SinnottArmstrong W, Howarth R (eds) Perspectives on climate change: science, economics, politics. Ethics. Elsevier, Amsterdam, pp 285-307

Soper K (2007) Re-thinking the 'good life': the citizenship dimension of consumer disaffection with consumerism. J Consum Cult 7:205-229. https://doi.org/10.1177/1469540507077681

Stoll-Kleemann S, O'Riordan T, Jaeger C (2001) The psychology of denial concerning climate mitigation measures: evidence from Swiss focus groups. Global Environ Chang 11:107-117. https://doi.org/10.1016 /S0959-3780(00)00061-3

Trump, D. (2017). Statement by President Trump on the Paris Climate Accord. 1 June 2017. https://www. whitehouse.gov/briefings-statements/statement-president-trump-paris-climate-accord/. Accessed 16 April 2019

UN (1992) The Rio Declaration on Environment and Development. http://www.unesco.org/education/pdf/RIO_ E.PDF. Accessed 16 April 2019

UN (2015) Adoption of the Paris Agreement. http://unfccc.int/resource/docs/2015/cop21/eng/109r01.pdf. Accessed 16 April 2019 
UNEP (2018) Emissions gap report 2018. United Nations Environment Programme, Nairobi. http://wedocs.unep. org/bitstream/handle/20.500.11822/26895/EGR2018_FullReport_EN.pdf? sequence=1\&isAllowed=y. Accessed 16 April 2019

Vandenbergh M, Barkenbusm J, Gilligan J (2008) Individual carbon emissions: the low-hanging fruit. UCLA Law Rev 55(6):1701-1758

Vanderheiden S (2008) Atmospheric justice: a political theory of climate change. Oxford University Press, Oxford

Ward B (2016) Is there a link between climate change 'sceptics' and Brexit supporters? http://blogs.lse.ac. uk/politicsandpolicy/tactics-of-climate-change-sceptics-and-vote-leave/. Accessed 16 April 2019

Watts N, Amann M, Ayeb-Karlsson S, Belesova K, Bouley T, Boykoff M, Byass P, Cai W, Campbell-Lendrum D, Chambers J, Cox PM, Daly M, Dasandi N, Davies M, Depledge M, Depoux A, Dominguez-Salas P, Drummond P, Ekins P, Flahault A, Frumkin H, Georgeson L, Ghanei M, Grace D, Graham H, Grojsman R, Haines A, Hamilton I, Hartinger S, Johnson A, Kelman I, Kiesewetter G, Kniveton D, Liang L, Lott M, Lowe R, Mace G, Odhiambo Sewe M, Maslin M, Mikhaylov S, Milner J, Latifi AM, Moradi-Lakeh M, Morrissey K, Murray K, Neville T, Nilsson M, Oreszczyn T, Owfi F, Pencheon D, Pye S, Rabbaniha M, Robinson E, Rocklöv J, Schütte S, Shumake-Guillemot J, Steinbach R, Tabatabaei M, Wheeler N, Wilkinson P, Gong P, Montgomery H, Costello A (2018) The lancet countdown on health and climate change: from 25 years of inaction to a global transformation for public health. Lancet 391:581-630. https://doi.org/10.1016/S0140-6736(17)32464-9

Weber E (2015) Climate change demands behavioral change: what are the challenges? Soc Res 82(3):561-580

WHO (2018) Climate change and health. http://www.who.int/news-room/fact-sheets/detail/climate-change-andhealth. Accessed 16 April 2019

Williams L, DeSteno D (2008) Pride and perseverance: the motivational role of pride. J Pers Soc Psychol 94: 1007-1017. https://doi.org/10.1037/0022-3514.94.6.1007

Publisher's Note Springer Nature remains neutral with regard to jurisdictional claims in published maps and institutional affiliations. 